\title{
Risk Diagnosis and Management with BBN for Civil Engineering Projects during Construction and Operation
}

\author{
Marian W. Kembłowski ${ }^{1}$, Beata Grzyl $^{1}$, Agata Siemaszko ${ }^{1 *}$, Adam Kristowski $^{1}$ \\ ${ }^{1}$ Faculty of Civil and Environmental Engineering, Gdansk University of Technology, Gdańsk, Poland
}

\begin{abstract}
The authors demonstrate how expert knowledge about the construction and operation phases combined with monitoring data can be utilized for the diagnosis and management of risks typical to large civil engineering projects. The methodology chosen for estimating the probabilities of risk elements is known as Bayesian Belief Networks (BBN). Using a BBN model one can keep on updating the risk event probabilities as the new evidence (monitoring information) becomes available. Furthermore, the updated probabilities estimated using the available data for the construction phase serve as background information for the subsequent phase. The integrated two-object model of construction-operation may be then used to optimize the decision making, thus minimizing the risks. To better show how the proposed approach works the authors use the example of the road tunnel constructed and operated under the Dead Vistula River in Gdansk.
\end{abstract}

\section{Introduction}

The authors demonstrate how expert knowledge about the construction and operation phases (CP and $\mathrm{OP}$ ) combined with monitoring data can be utilized for the diagnosis and management of risks typical to large civil engineering projects $[1,2]$. The methodology selected for estimating the probabilities of risk events is known as Bayesian Belief Networks (BBN). Using a projectspecific BBN model one can keep on updating the risk event probabilities as new evidence (monitoring information/observations) becomes available. Furthermore, the probabilities estimated during the final period of the construction phase with the help the thenavailable observations serve as background (prior) information for the subsequent (operation) phase (in BBN lingo: the next object). The integrated two-object, construction-operation, model may be used to optimize the decision making process, thus minimizing project risks. To better show how the proposed approach works the authors use the example of the road tunnel constructed and operated under the Dead Vistula River in Gdansk, utilizing the data from tunnel construction subsidence measurements. The importance of the monitoring data collected during the construction activities to risk management during the project operation is demonstrated. We also show how this information affects the estimates of operational risk event probabilities. Some of the risk events that ought to be considered are the occurrence of leaks during the tunnel construction and (improper) subsidence of the tunnel. Such problems may subsequently lead during the tunnel operation to weakening of the tunnel body, and then to growing cracks in the structure. The symptoms of this potential problem can be monitored during tunnel operation.

\section{The project description}

The project "Connection of Gdańsk Airport with the Port of Gdańsk. The Słowacki Route. Task IV" is part of a broader one (the overall route length is approx. $10 \mathrm{~km}$ ). The enterprise covers four project tasks of construction and reconstruction of subsequent sections of Słowacki Route, located between the Lech Walesa Airport of Gdansk and the Ku Ujściu traffic interchange.

The major aims of the project are efficiency rise of the Airport - Port of Gdańsk connection, traffic improvement and city development. The Dead Vistula River passage is the project component, implemented by a highway tunnel. Drilling method is applied here on the $1072,5 \mathrm{~m}$ long section, by means of the TBM (Tunnel Boring Machine), which includes a 12.6-metre diameter shield.

The Task IV concerning a $2.4 \mathrm{~km}$ section covered (see Fig. 1, Fig. 2):

- Słowacki Route construction on the section: Marynarki Polskiej Str. - Ku Ujściu interchange.

- Erecting a $2159 \mathrm{~m}$ long engineering structure, including the Dead Vistula River Tunnel (Fig. 3) 1377.5 $\mathrm{m}$ long, consisting of two parallel tunnels for each traffic direction separately, including two lanes of traffic.

- Building the Marynarki Polskiej interchange, covering a large roundabout (traffic circle) of a $130 \mathrm{~m}$ external diameter, complemented by 7 engineering objects (two road viaducts, a tramway viaduct, two technical viaducts

\footnotetext{
* Corresponding author: agata.siemaszko@pg.edu.pl
} 
supporting the underground installations along the Marynarki Polskiej St. and two objects for the pedestrians and cyclists).

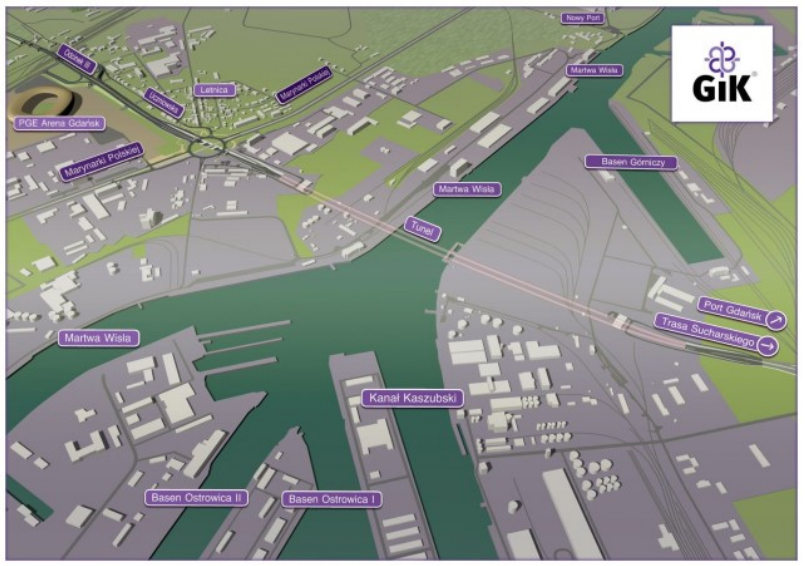

Fig. 1. Słowacki Route construction - the Task IV, source: http://www.gik.gda.pl/34/inwestycje/budowa_trasy_slowackie go/zadanie_iv.html, access date: 28.06.2015.

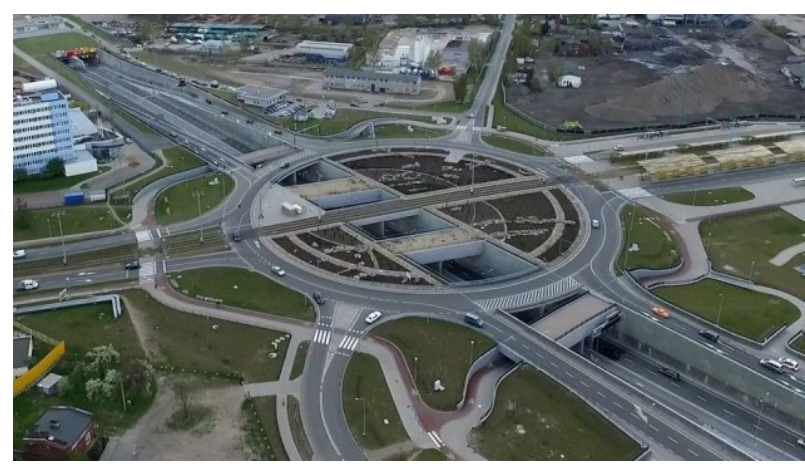

Fig. 2. Słowacki Route construction - the Task IV, source: http://www.gik.gda.pl/34/inwestycje/budowa_trasy_slowackie go/zadanie_iv.html, access date: 28.06.2015.

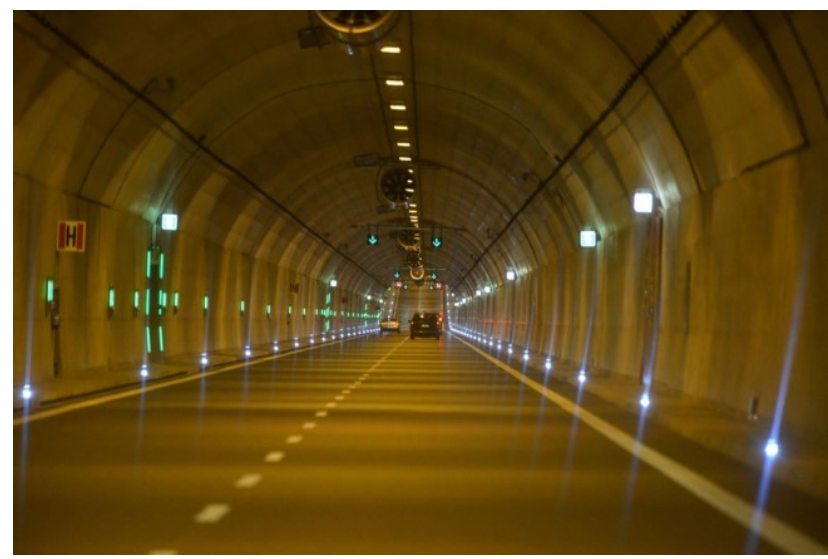

Fig. 3. Słowacki Route construction - the Task IV, source: http://www.gik.gda.pl/34/inwestycje/budowa_trasy_slowackie go/zadanie_iv.html, access date: 28.06.2015.
The ordering party was Gdańsk Commune, represented by Gdańskie Inwestycje Komunalne Sp. z o.o. (GIK Sp. z o.o.). Europrojekt Gdańsk S.A. and SSF Ingenieure $\mathrm{GmbH}$ were designers. The contractor was a Spanish company Obrascon Huarte Latin S.A. (OHL).

The tunnel construction is a specified and individual task, involving a number of significant threats. As a result of insufficient background knowledge on the threats connected with tunnel works and their prevention the British Tunnel Society (BTS) published a document "Joint Code of Practice for Risk Management of Tunnel Works in the UK". The code was a joint work of the BTS and British insurance companies. The discussions between the International Tunnel Association (ITA) and the International Association of Engineering Insurers (IMIA) made the code modification and adaptation to international standards. The Code was published again in January 2006 by International Tunnel Insurance Group (ITIG). Its major aim is traffic incident reduction by means of a proper risk identification and effective reduction of risk level at the design and work execution stages of tunnels, caves, shafts and underground connections, complemented by renovation of existing underground infrastructure. The code is a valuable information source now on the best practice in risk management in the related field.

The Bayesian networks are available tools to analyze the risk linked with design, work execution and operation of building projects. The authors suggest to incorporate Bayesian networks for the risk assessment of a investment project - a giant, technologically demanding, highly cost consuming and unique in a country scale - The highway Dead Vistula River Tunnel.

\section{Application of BBNs to a tunnel construction and operation project}

We are concerned with risk analysis and management for the phases of construction and operation of a tunnel [3]. Specifically, we are interested in integrating the management of the two phases [4]. Our management model for the construction phase was described in [5]. We assume that the risk analysis information is passed from the construction phase to the operation phase. This is done by estimating for the construction phase the probabilities of two variables:

- tunnel (improper) subsidence,

- faulty element sealing (see Fig. 4).

This information affects in turn the probabilities of two major decision variables for the operation phase, namely: Tunnel Damage, and Tunnel Leaks. These probabilities could be also changed by downward propagation of the information (when available) from: Soil Testing, and tunnel Tightness Monitoring. Finally, these probabilities may be updated by back propagation of the evidence regarding two symptoms: Tunnel Cracks, and Moisture of Tunnel Surface. 


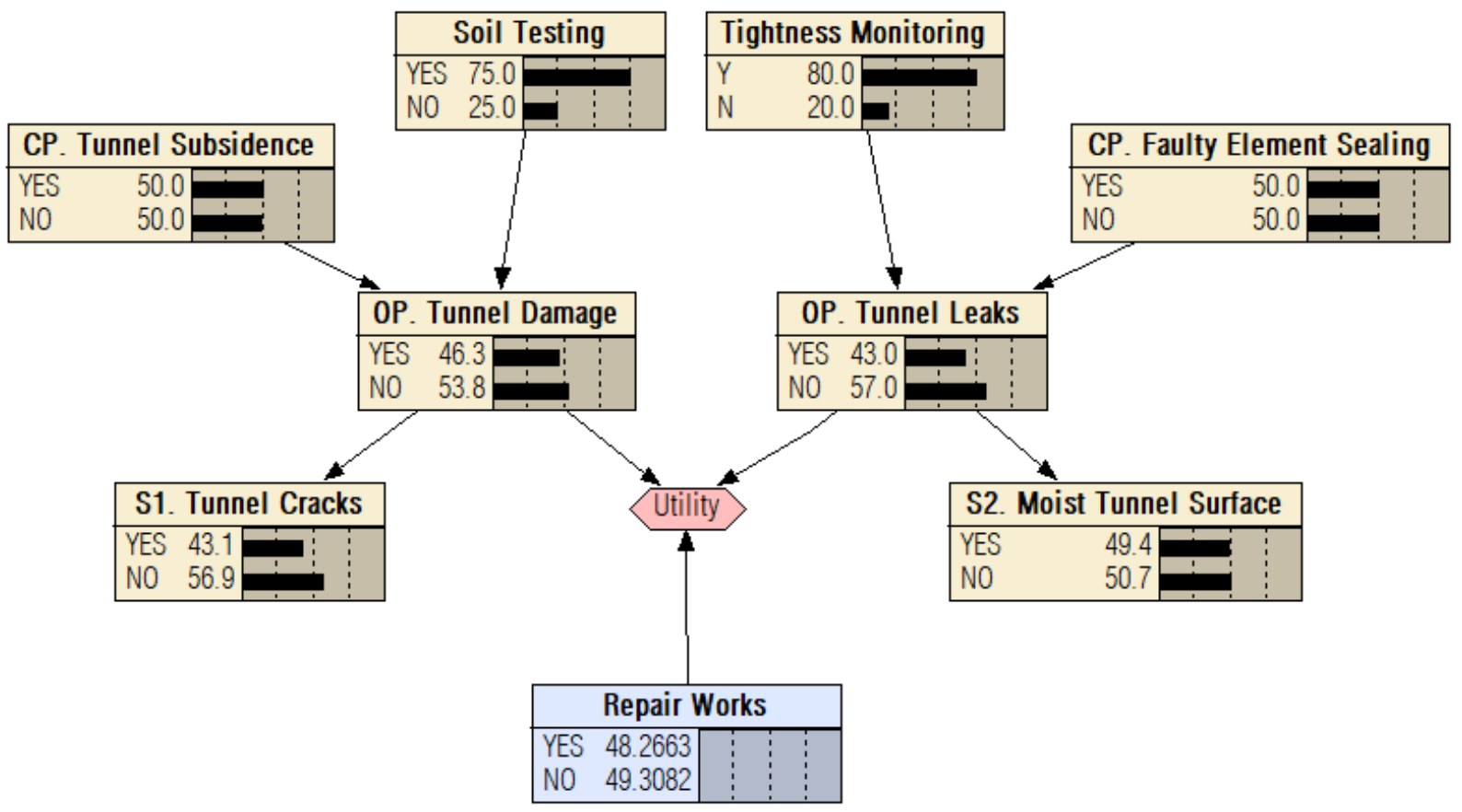

Fig. 4. Bayesian Net for the Tunnel Example.

Fig. 4 shows the connections between the nodes/variables. The strength of the connections is coded in the Bayesian Network by conditional probabilities [5, 6]. In our example the Bayesian Diagnostic/Decision Net Model is used to decide whether to undertake Tunnel Repair Works [10]. In order to do that we define the Utility table, i.e., the utility of each decision for all the combinations of decision variables.

To demonstrate the usefulness of a BBN model to decision making, and thus risk analysis and management, we briefly present and discuss some simulation results [11] obtained using NETICA application. For simplicity we selected as our base scenario (see Fig. 4) the situation where from the construction phase we obtain the information about the two principal variables that is characterized by high entropy. Specifically, we assume 50/50 probabilities of the states (Yes and No) of: Tunnel (improper) Subsidence and Faulty Element Sealing. We also assume that initially we have no new evidence from monitoring the symptoms (Tunnel Cracks, and Moisture of Tunnel Surface). Then we proceed to estimate the expected utilities for different scenarios by changing the information passed from construction phase and introducing new evidence from symptom monitoring.

The first scenario is presented in detail in Fig. 5. It concerns the risk of tunnel settlement due to draining by a TMB machine (Tunnel Subsidence - YES 100\%). In the operational stage cracks are observed making it difficult or even impossible to explore the tunnel (Tunnel Craks - YES 100\%). These means may lead to the estimation of a decision-change value. Consequently the repair works should start (the YES decision of a 68.42 value).
In the second scenario shown in Fig. 6 the risk is also assumed of tunnel settlement during construction, due to drilling by means of a TMB machine (Tunnel Subsidence - YES 100\%). However, the survey during operation detects neither scratches nor cracks in the tunnel structure

(Tunnel Subsidence - NO 100\%). This case means the decision change to YES (YES - 49.85). The outlined procedure is a decision-supporting means provided by a tunnel manager. It was correctly assumed that the operation stage is backed up by structural measurements and monitoring.

The measurement discrepancies from the operational ones sign the anomalies, next a decision is made either to start or not the repair activities in the tunnel. The authors' inquiries focus on the tunnel damages and breaking structural tightness. These cases are highly dangerous due to safety of the structure and its users. The damages in the operational stage are triggered e.g. by erecting conditions. In order to avoid such events verification and accounted update of the achieved parameters on the work execution stage of a tunnel construction. This concerns the designed soil-water parameters, next updated due to real conditions affecting tunnel operation, correction of the decision-making parameters, with a continuous update given actual, up-to-date information.

The simulation results are presented in Table 1. Thus observation is possible how the decision value evolved due to risk assessment of unexpected events during the tunnel construction and comparing it with observations of tunnel operation.

A brief analysis of the results shows the relative importance of two issues:

- Information about the tunnel state passed from the construction phase to the operation phase (in here: Tunnel Subsidence and Faulty Element Sealing),

\footnotetext{
* Corresbonding author: agata.siemaszko@.ng.edu.nl
} 
- Observing of the tunnel behavior (symptoms) during the operation phase (in here: monitoring Tunnel Cracks, and Moisture of Tunnel Surface).

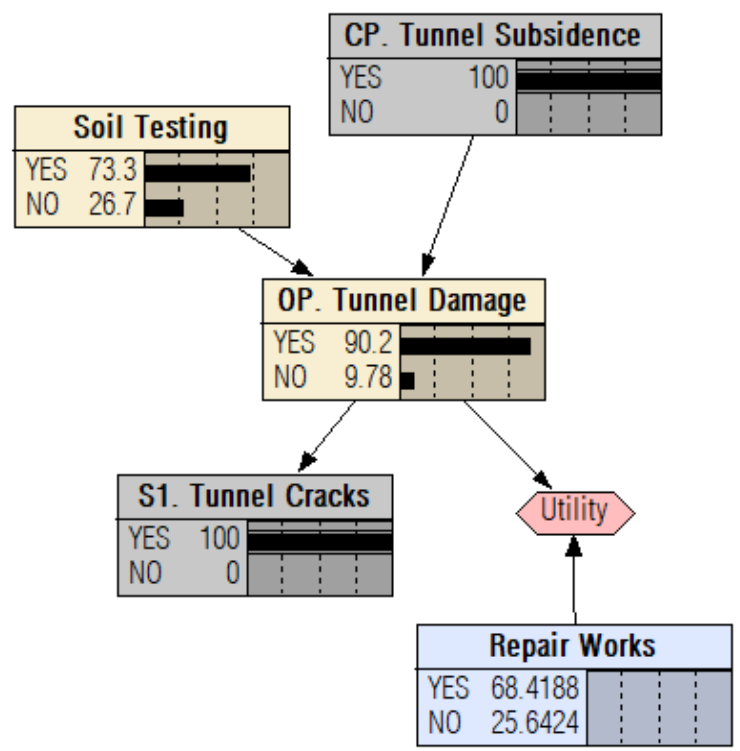

Fig. 5. Network simulation example No. 1

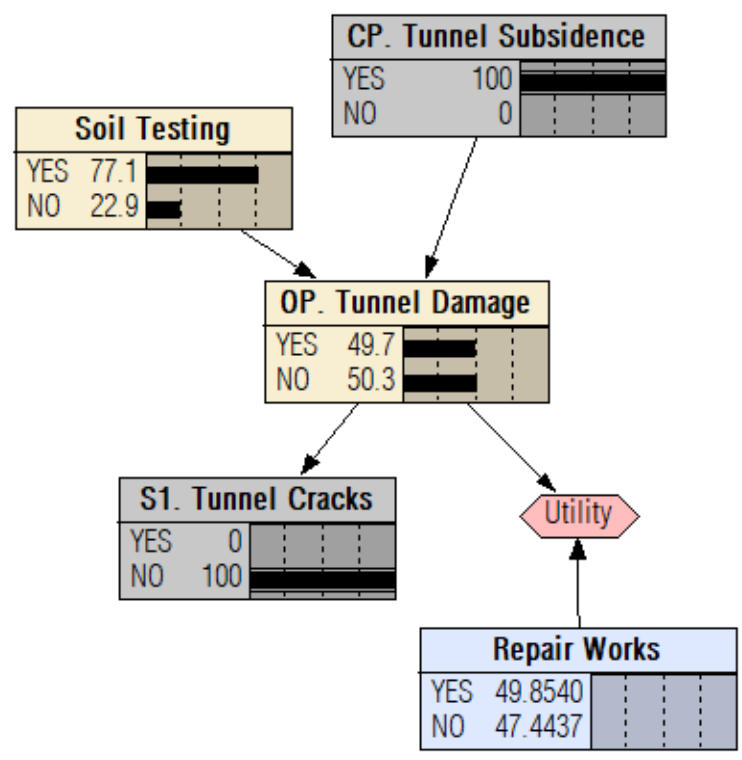

Fig. 6. Network simulation example No. 2.

It is clear that our decision depends strongly on this information. Furthermore, a wrong decision that does not take into account all sources of information may lead to considerable losses. For example: for high entropy information from the construction phase and no symptom information from the tunnel operation phase, Row 1 in Table I, we ought to choose the no Works decision with utility $U=49.31$. However, if in reality we have faulty element sealing during the construction phase plus observe leaks during operation (the scenario highlighted in Table 1), and make the same decision not taking account the new evidence, we end up with the utility of $U=27.87$. This is a significant utility loss compared to the optimal value (for Repair Works $=$ Yes) of expected utility for this case, namely $U=66.23$. The difference may be understood as the risk of making wrong decisions due to the fact of not taking rigorously into account the evidence. A BBN diagnostic/decision tool allows us to avoid this type of risks by taking into account all available evidence and combining it with the expert knowledge (model). It also enables us to estimate expected value of monitoring data - pre a posteriori analysis $[7,8,9]$.

Table 1. Summary of simulation scenarios and results.

\begin{tabular}{|c|c|c|c|c|c|}
\hline \multirow{2}{*}{ 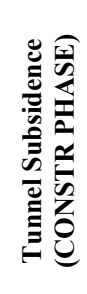 } & \multirow{2}{*}{ 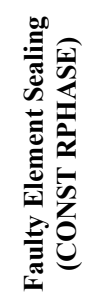 } & \multirow{2}{*}{ 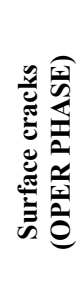 } & \multirow{2}{*}{ 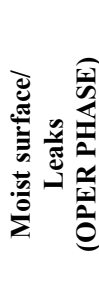 } & \multicolumn{2}{|c|}{$\begin{array}{l}\text { Expected Utility of } \\
\text { Repair Works } \\
\text { Decision }\end{array}$} \\
\hline & & & & Yes & No \\
\hline $50 / 50$ & $50 / 50$ & - & - & 48.26 & 49.31 \\
\hline Yes & $\mathbf{5 0 / 5 0}$ & Yes & - & 68.4188 & 25.6424 \\
\hline Yes & $\mathbf{5 0 / 5 0}$ & No & - & 49.8540 & 47.4437 \\
\hline $50 / 50$ & Yes & - & Yes & 66.2323 & 27.8741 \\
\hline $50 / 50$ & No & - & No & 32.8424 & 67.7095 \\
\hline $50 / 50$ & No & - & Yes & 51.5269 & 45.4752 \\
\hline
\end{tabular}

\section{Summary}

The major advantage of the proposed methodology lies in the fact that a created construction-operation risk model works as an integrating tool in which both past and current information about the project and the surrounding conditions is used to assess the risk problems' probabilities at any time of interest. The selection of optimal decisions, based on the assessed probabilities of risk events $[12,13]$, may be performed, from the viewpoints of the contractor and/or investor. The application of such a Bayesian network model allows one to consider/evaluate decision risks in the environment characterized by considerable uncertainty. The model combines the expert knowledge of the risk problem elements and the cause-effect relationships among them (whose strength is expressed by conditional probabilities) with new evidence (monitoring observations). The evidence from such observations is propagated throughout the whole network resulting in updated (a posteriori) probabilities of the events/variables represented in the model. The updated risk probabilities that reflect the cumulative effect of all new evidence may lead us in turn to new (updated) selection of optimal decisions. 
It is worthwhile to mention that the model variables and the relationships among them are represented by easy to understand, discuss, and modify graphs. This characteristic is of importance during the process of creating and testing the model by a group of problem experts and knowledge engineers.

Furthermore, as our knowledge regarding new factors influencing risk issues becomes broader we may readily incorporate the new relationships in our integral risk model. This is due to the elasticity of Bayesian nets, namely their ability to accept new interconnected events with multiple connections to the existing one.

\section{References}

1. Polska Norma PN-EN 60300-3-3:2006 „Część 3-3: Przewodnik zastosowań. Szacowanie kosztu cyklu życia" (2006) (in polish)

2. M. Apollo and E. Urbańska-Galewska, Model of Risk Assessment (MORA) concept for the investment part of urban regeneration projects, Environmental Engineering, Proceedings of the International Conference on Environmental Engineering. ICEE. 9. (2014)

3. B. Grzyl and A. Kristowski, BIM jako narzędzie wspomagajace zarzadzanie ryzykiem przedsięwzięcia inwestycyjnego, Materiały Budowlane, 6, pp. 52-54, (2016) DOI: 10.15199/33.2016.06.22

4. E. Miszewska-Urbańska, Modern Management Challenges of Floating Housing Development, Real Estate Management and Valuation, 24, issue 1, pp. 31-40, (2016)

5. M. W. Kembłowski, B. Grzyl, A. Kristowski, and A. Siemaszko, Risk Modelling with Bayesian Networks - Case Study: Construction of Tunnel under the Dead Vistula River in Gdansk, Procedia Engineering 196, 585-591, (2017)

6. U. B. Kjaerulff and A. L. Madsen, Bayesian Networks and Influence Diagrams. A Guide to Construction and Analysis, Springer Science+Business Media, LLC, (2008)

7. Norsys. [Online] Available: http://www.norsys.com/netica. [Accessed: 09.2017]

8. M. Miskiewicz, L. Pyrzowski, and K. Wilde, Structural Health Monitoring System for Suspension Footbridge, in Proc. of 2017 Baltic Geodetic Congress (BGC Geomatics), pp. 321-325, (2017) DOI: 10.1109/BGC.Geomatics.2017.8

9. M. Apollo, E Miszewska-Urbańska, Analysis of the increase of construction costs in urban regeneration projects, Advances in Science and Technology Research Journal, 9.28, (2015)

10. M. Kurpińska and A. Małasiewicz, "Der Betonschutz vor der Wirkung der aggressiven Umbebung," Ibausil 15.Internationale Baustofftagung 24 -27 September 2003, F.A. Finger - Institut für Baustoffkunde, Bauhaus-Universität
Weimar, Weimar, Bundesrepublik Deutschland, 20943 - 2-0952, (2003)

11. D. Fudenberg and J. Tirole, Game Theory, MIT Press, (1991)

12. J. Levin, Dynamic Games with Incomplete Information, February (2002), http://web.stanford.edu/ jdlevin/Econ\%20203/Dyna micGames.pdf

13. N. Fenton, M. Neil, Risk Assessment and Decision Analysis with Bayesian Networks, CRC Press, ISBN: 9781439809105, (2012) 